\title{
Empirical and Statistical Determination of Optimal Distribution Model for Radio Frequency Mobile Networks Using Realistic Weekly Block Call Rates Indicator
}

\author{
Divine O. Ojuh \\ Department of Physical Sciences, Faculty of Sciences, Benson Idahosa University, Benin City, Edo State \\ Emails: dojuh@biu.edu.ng \\ Joseph Isabona \\ Department of Physics, Faculty of Science, Federal University Lokoja, PMB. 1154, Lokoja, Kogi State \\ Emails: josabone@yahoo.com, joseph.isabona@fulkoja.edu.ng
}

Received: 18 March 2021; Accepted: 10 May 2021; Published: 08 August 2021

\begin{abstract}
Mobile phones and handsets enable us to communicate our voice, data and video messages with individuals that are far-off from us. When an active call is initiated by someone using a mobile phone, it is transmitted through a nearby Base Station (BS) transmitter to another BS until the call gets to its intended receiver. Any time a caller initiates and loses a connection to a BS while on conversation, the call is said to be dropped. The initiation and completion of an active call without any form of disconnection or termination is a key service quality parameter in telecommunication system networks. Robust statistical estimation, modelling and characterization of call drop rates is of high importance to the network operators and radio frequency engineers for effective re-planning and performance management process of telecommunication system networks. This work was designed to determine the optimal probability distribution model for drop call rates based on a five week acquired rate of drop calls data sample in the Southern regions of Nigeria. To accomplish the aim, eight probability distributions namely logistic, log-logistic, normal, log-normal, exponential, Rayleigh, rician and Gumbel max were explored and based on the combined scores of three goodness of fit statistical tests, the log-logistic distribution was found to be the optimal probability distribution for the weekly rate of drop call prognostic analysis. The results could be of immense assistance to radio frequency engineers for optimal statistical modelling and design of cellular systems channels.
\end{abstract}

Index Terms: Block calls, Drop calls, modelling, optimal probability distribution, goodness-of-fit, log-logistic, prognostic analysis

\section{Introduction}

The telecommunication industrial sector has gone through a remarkable technological growth and advancement over the years, globally. This can be seen in the steady evolution and rolling out of varied cellular radio communication technology such as UMTS (Universal Mobile telecommunication Systems, GSM (Global system for Mobile Communication), LTE (Long Term Evolution) and among others. The deployment and smooth acceptance of these cellular radio communication system networks in our society has also been on the rise daily in the recent years and it keeps rising globally. This has as well been accompanied by large subscription of both personal and commercial subscribers to the various voice, data and video services being offered by the system networks operators or service providers.

As the evolution, deployment and urbane acceptance these different cellular radio communication, systems continuous to grow, complemented with the interminable increase in their service package subscriptions, one important aspect that cannot be overlooked is the level of satisfaction the subscribers obtain from the assorted services network operators to the subscribers. Based on different research studies [1]-[4], it is disclosed that subscribers' frustration with regard to quality of service (QoS) is the main reason why about $82 \%$ of them constantly change network operator or subscribe to more than one operator. One of the foremost problems that leads to mobile subscribers' complains and frustration is the problem of call drops while on conversation in cellular radio communication networks. In many 
reports, poor network planning, free channels unavailability, high traffic rate, poor antenna engineering configuration, etc., have been identified as the key factors that result to frequent call dropping in cellular communication systems.

\section{Literature Review}

In literature, different attempts have been adopted to examine and model the rate of call drops in cellular mobile networks, but mostly through theoretical and analytical methods [5]-[14], which are too complex and impracticable to explore during network planning/re-planning phase [15-19]. In [20-29], the authors engaged combined theoretical survey and analytical methods to study wireless network performance using some key performance indicators such as signal quality [20, 21], blocking/dropping probabilities in [22- 25], grade of service in [26], traffic delay in [27], outage probability in [28], spectral efficiency in [29], and cell availability in [30], respectively.

The work is proposed to realistically find an optimal reliable statistical distribution model that can characterizes and prognostically analyze the rate of practical drop calls data sample acquired over cellular radio network in the Southern regions of Nigeria.

\section{Materials and Methods}

Statistical probability distributions are specially formulated distributions by statisticians to mathematically represent or model certain distributional phenomenon. In this work, eight special probability distribution functions (pdfs) and their cumulative distribution functions (cdfs) are explored to model and prognostically characterize the week rate of drop calls acquired over operational cellular mobile radio networks. The eight special probability distributions are logistic, log-logistic, normal, log-normal, exponential, Rayleigh, rician and Gumbel max. The performance of each the eight special probability distributions would be conveyed using goodness of fit (GOF) statistics such as the Kolmogorov Smirnov test, Chi-Square Test and Anderson Test.

\subsection{Log-logistic probability Distribution (LLPD)}

The LLPD is a robust distribution model whose variables are logistically distributed. The pdf and cdf, mean, mode, variance, skewness and Kurtosis can be expressed by is given by:

$$
\begin{gathered}
f(x)=\frac{\mu x^{\mu-1}}{k^{\mu}\left[1+\frac{x}{k}\right]^{2}} \\
F(x)=\frac{1}{1+\left[\frac{k}{x}\right]^{\mu}} \\
\text { Mean }=k\left(\frac{\pi}{\mu}\right) \csc \left(\frac{\pi}{\mu}\right) \\
\text { Mode }=k\left[\frac{\mu-1}{\mu+1}\right]^{\frac{1}{\mu}}
\end{gathered}
$$




$$
\text { Curtosis }=\frac{6\left(\frac{\pi}{\mu}\right)^{2} \csc ^{3}\left(\frac{\pi}{\mu}\right) \sec \left(\frac{\pi}{\mu}\right)+4 \csc \left(4 \frac{\pi}{\mu}\right)-3\left(\frac{\pi}{\mu}\right)^{3} \csc ^{4}\left(\frac{\pi}{\mu}\right)-12 \csc \left(\frac{\pi}{\mu}\right) \csc \left(3 \frac{\pi}{\mu}\right)}{\frac{\pi}{\mu}\left[2 \csc \left(2 \frac{\pi}{\mu}\right)-\frac{\pi}{\mu} \csc ^{2}\left(\frac{\pi}{\mu}\right)\right]^{2}}-3
$$

where $\mu$ and $k$ represent the location and scale parameters.

\subsection{Logistic probability Distribution (LPD)}

The LPD is a distribution with varied application; it is used for life data analysis, logistic regression analysis and also for growth modeling. The lognormal PDF and CDF can be defined by:

$$
\begin{gathered}
f(x)=\frac{\exp -(x-\mu) / k}{k(1+\exp -(x-\mu) / k)^{2}} \\
F(x) \frac{1}{1+\exp -(x-\mu) / k}
\end{gathered}
$$

where $\mu$ and $k$ represent the location and scale parameters. The variance of the distribution is given by:

$$
\text { Variance }=\frac{k^{2} \pi^{2}}{3}
$$

\subsection{Lognormal Distribution Function (LNPD)}

The LNPD is also a special distribution is whose random variables with a normally distributed logarithm. The lognormal PDF and CDF can be defined by [31].

$$
\begin{aligned}
& f(x)=\frac{1}{x k \sqrt{2 \pi}} \exp \left[\frac{-(\ln x-\mu)^{2}}{2 k^{2}}\right] \\
& F(x)=\frac{1}{2}+\frac{1}{2} \operatorname{erf}\left[\frac{-(\ln x-\mu)^{2}}{\sqrt{2} k}\right]
\end{aligned}
$$

where $\mu$ and $k$ represent the location and scale parameters.

\subsection{Normal Distribution}

The normal distribution remain one of the most applied distribution for data analysis. The normal PDF and PDF can be determine using [31]:

$$
\begin{gathered}
f(x)=\frac{1}{k \sqrt{2 \pi}} \exp \left[\frac{-(x-\mu)^{2}}{2 k^{2}}\right] \\
F(x)=\frac{1}{2}\left[1+\operatorname{erf}\left(\frac{(x-\mu)}{k \sqrt{2}}\right)\right]
\end{gathered}
$$

where $\mu$ and $k$ represent the location and scale parameters.

\subsection{Gumbel Distribution}

The Gumbel distribution, also generally termed the Extreme Value Type I (EV I) distribution, is named in honor of Emil Gumbel. The lognormal pdf and cdf of this distribution can be defined by (Isabona, 2019) 


$$
\begin{gathered}
f(x)=\frac{1}{k} \exp \left[\frac{-(x-\mu)}{k}-\exp \frac{-(x-\mu)}{k}\right] \\
F(x)=\exp \left(-\exp \frac{-(x-\mu)}{k}\right)
\end{gathered}
$$

where $\mu$ and $k$ represent the location and scale parameters.

\subsection{Exponential Distribution}

This is one of most extensively explored continuous distribution, especially for modeling the elapse time between events. The pdf and cdf of exponential distribution can be determine using:

$$
\begin{aligned}
& f(x)=\frac{1}{k} \exp -\left[\frac{x-\mu}{k}\right] \\
& F(x)=1-\exp -\left[\frac{x-\mu}{k}\right]
\end{aligned}
$$

where $\mu$ and $k$ represent the location and scale parameters.

\subsection{Rayleigh Distribution}

The Rayleigh distribution is a popularly used continuous probability distribution and also a special (singular) case of the Weibull distribution. The Rayleigh pdf and cdf are given by [31,32]:

$$
\begin{gathered}
f(x)=\frac{x}{k} \exp \left[-\left(\frac{-x^{2}}{2 k^{2}}\right)\right] \\
F(x, \sigma)=1-\exp \left[-\left(\frac{-x^{2}}{2 k^{2}}\right)\right]
\end{gathered}
$$

where $\mu$ and $k$ represent the location and scale parameters.

\subsection{Nakagami Distribution Function}

The Nakagami distribution, is another well-known distribution termed the Nakagami- $m$ distribution behave roughly and evenly near its mean value. The Nakagami pdf and cdf can expressed as [31]:

$$
\begin{gathered}
f()=\frac{2 m^{m}}{\Gamma(m) a^{m}} x^{2 m-1} \exp \left[-\frac{m}{a} x^{2}\right] \\
F(x, m, \Omega)=\frac{Y\left(m, \frac{m}{a} x^{2}\right)}{\Gamma(m)}
\end{gathered}
$$

In (21), $\mu$ and $\omega$ represent the location and scale distribution parameters for the Nakagami.

\subsection{Rician Distribution Function}

In communication, the Rician distributions functions are usually employed to study stronger line-of-sight fading channels. The Rician PDF and CDF can expressed as [31]:

$$
f(x)=\frac{x}{k^{2}} \exp \left[\left(\frac{-x^{2}+v^{2}}{2 k^{2}}\right) I_{o}\left(\frac{x v}{k^{2}}\right)\right]
$$




$$
F(x)=1-Q_{1}\left(\frac{v}{k}, \frac{x}{k}\right)
$$

In (23), $\mu$ and $k$ represent the location and scale distribution parameters for the Rician. where $I_{o}(z)$ and $Q_{1}(z)$ represent the modified Bessel function and Marcum Q function, respectively.

\section{Results and Analysis}

The five weeks drop call rate data explored for this study was obtained from the Radio network controller (RNC) stations of an operative GSM/UMTS system networks service provider operating Southern Nigeria. The number of NodeBs transceivers engaged in the data collection were 120. The results in Table 1 contain the weekly call drop statistics at a glance using EasyFit 5.6 Software. The graphics were also done using the EasyFit 5.6 Software. The results reveal that the table that the mean drop call rates ranges from 0.75 to 0.33 values, which are all within the $5 \%$ (0.02) threshold for GSM/UMTS networks.

To determine the optimal probability distribution model for weekly drop call rates data, we explored three goodness of fit (GOF) statistical tools such as the Kolmogorov Smirnov test, Chi-Square Test and Anderson Test. Tables 2 (a) - 6 (a), show the goodness of fit results using Kolmogorov Smirnov test, Anderson test and Chi-square test. To accomplish the aim, eight probability distributions namely logistic, log-logistic, normal, log-normal, exponential, Rayleigh, Rician and Gumbel max were explored and based on the combined scores of three goodness of fit statistical tests in Tables 2 (b) - 6 (b), the log-logistic distribution was found to be the be optimal probability distribution for the weekly rate of drop call prognostic analysis. For the purpose of visibility, the respective plotted pdf and cdf graphs using the log-logistic distribution are shown in Figs. 1 (a)-5(a) and Figs.1 (b)-5(b).

Table 1. Results of the weekly call drop rate statistics at a glance

\begin{tabular}{|l|l|l|l|l|c|}
\hline Statistic & Week 1 & Week 2 & Week 3 & Week 4 & Week 5 \\
\hline Mean & 0.46 & 0.33 & 0.37 & 0.73 & 0.72 \\
\hline Variance & 0.85 & 0.61 & 0.88 & 5.07 & 2.98 \\
\hline Std. Deviation & 0.92 & 0.78 & 0.94 & 2.25 & 1.72 \\
\hline Range & 4.75 & 3.30 & 5.34 & 14.08 & 9.55 \\
\hline Coef. of Variation & 1.97 & 2.33 & 2.52 & 3.07 & 2.39 \\
\hline Std. Error & 0.13 & 0.11 & 0.13 & 0.32 & 0.24 \\
\hline Skewness & 3.11 & 3.17 & 3.89 & 4.99 & 3.51 \\
\hline Excess Kurtosis & 10.63 & 9.38 & 17.25 & 27.59 & 14.35 \\
\hline
\end{tabular}

Table 2 (a): Goodness of Fit tests on week 1 call drop rates

\begin{tabular}{|c|c|c|c|}
\hline Week 1 & $\begin{array}{l}\text { Kolmogorov } \\
\text { Smirnov test }\end{array}$ & Anderson Test & Chi-Square Test \\
\hline Logistic & 0.28484 & 7.4128 & 15.744 \\
\hline Log-logistic & 0.12245 & 9.0142 & 1.252 \\
\hline Normal & 0.30588 & 7.7838 & 13.744 \\
\hline Log-normal & 0.15962 & 10.445 & 9.2907 \\
\hline Gumbel & 0.34077 & 6.1854 & 7.5814 \\
\hline Exponential & 0.35526 & 40.125 & 38.002 \\
\hline Rayleigh & 0.5252 & 83.414 & 76.755 \\
\hline Rician & 0.62478 & 132.83 & 122.31 \\
\hline
\end{tabular}

Table 2 (b): Goodness of Fit tests score on week 1 call drop rates

\begin{tabular}{|c|c|c|c|}
\hline Week 1 & $\begin{array}{l}\text { Kolmogorov } \\
\text { Smirnov test }\end{array}$ & Anderson Test & Chi-Square Test \\
\hline Logistic & 33 & 7 & 35 \\
\hline Log-logistic & 1 & 13 & 3 \\
\hline Normal & 35 & 26 & 32 \\
\hline Log-normal & 7 & 5 & 22 \\
\hline Gumbel & 38 & 44 & 41 \\
\hline Exponential & 42 & 46 & 43 \\
\hline Rayleigh & 46 & 48 & 45 \\
\hline Rician & 48 & & \\
\hline
\end{tabular}


Table 3 (a): Goodness of Fit tests on week 2 call drop rates

\begin{tabular}{|c|c|c|c|}
\hline Week 2 & $\begin{array}{l}\text { Kolmogorov } \\
\text { Smirnov test }\end{array}$ & Anderson Test & Chi-Square Test \\
\hline Logistic & 0.33418 & 9.9241 & 19.314 \\
\hline Log-logistic & 0.06508 & 5.1312 & 1.2203 \\
\hline Normal & 0.3343 & 10.378 & 19.63 \\
\hline Log-normal & 0.10735 & 5.4515 & 1.8956 \\
\hline Gumbel & 0.37833 & 0.37833 & 12.543 \\
\hline Exponential & 0.42531 & 30.46 & 60.754 \\
\hline Rayleigh & 0.5986 & 95.112 & 93.75 \\
\hline Rician & 0.70252 & 153.21 & 153.6 \\
\hline
\end{tabular}

Table 3 (b):Goodness of Fit tests score on week 2 call drop rates

\begin{tabular}{|c|c|c|c|}
\hline Week 2 & $\begin{array}{l}\text { Kolmogorov } \\
\text { Smirnov test }\end{array}$ & Anderson Test & Chi-Square Test \\
\hline Logistic & 33 & 29 & 30 \\
\hline Log-logistic & 1 & 4 & 4 \\
\hline Normal & 32 & 32 & 21 \\
\hline Log-normal & 15 & 11 & 27 \\
\hline Gumbel & 37 & 27 & 37 \\
\hline Exponential & 41 & 40 & 39 \\
\hline Rayleigh & 44 & 44 & 40 \\
\hline Rician & 45 & 45 & \\
\hline
\end{tabular}

Table 4 (a):Goodness of Fit tests on week 3 call drop rates

\begin{tabular}{|c|c|c|c|}
\hline Week 3 & $\begin{array}{l}\text { Kolmogorov } \\
\text { Smirnov test }\end{array}$ & Anderson Test & Chi-Square Test \\
\hline Logistic & 0.3613 & 9.7808 & 18.942 \\
\hline Log-logistic & 0.20945 & 12.255 & 13.424 \\
\hline Normal & 0.34856 & 10.016 & 19.914 \\
\hline Log-normal & 0.21815 & 12.772 & 13.081 \\
\hline Gumbel & 0.39366 & 8.7466 & 12.774 \\
\hline Exponential & 0.48273 & 75.936 & 60.40 \\
\hline Rayleigh & 0.66823 & 140.72 & 119.63 \\
\hline Rician & 0.73453 & 217.86 & 153.6 \\
\hline
\end{tabular}

Table 4 (b): Goodness of Fit tests score on week 3 call drop rates

\begin{tabular}{|c|c|c|c|}
\hline Week 3 & $\begin{array}{c}\text { Kolmogorov Smirnov } \\
\text { test }\end{array}$ & Anderson Test & Chi-Square Test \\
\hline Logistic & 31 & 7 & 32 \\
\hline Log-logistic & 6 & 13 & 20 \\
\hline Normal & 30 & 9 & 34 \\
\hline Log-normal & 20 & 21 & 17 \\
\hline Gumbel & 36 & 5 & 14 \\
\hline Exponential & 42 & 1 & 44 \\
\hline Rayleigh & 47 & 48 & 44 \\
\hline Rician & 48 & 49 & 45 \\
\hline
\end{tabular}

Table 5 (a): Goodness of Fit tests on week 4 call drop rates

\begin{tabular}{|c|c|c|c|}
\hline Week 4 & $\begin{array}{c}\text { Kolmogorov } \\
\text { Smirnov test }\end{array}$ & Anderson Test & Chi-Square Test \\
\hline Logistic & 0.36122 & 11.101 & 23.456 \\
\hline Log-logistic & 0.2500 & 13.027 & 10.555 \\
\hline Normal & 0.37251 & 11.492 & 21.645 \\
\hline Log-normal & 0.29769 & 17.443 & 19.756 \\
\hline Gumbel & 0.42655 & 10.36 & 13.982 \\
\hline Exponential & 0.49057 & 118.68 & 72.938 \\
\hline Rayleigh & 0.66207 & 134.12 & 118.1 \\
\hline Rician & 0.78421 & 245.16 & 173.4 \\
\hline
\end{tabular}


Table 5 (b): Goodness of Fit tests score on week 4 call drop rates

\begin{tabular}{|c|c|c|c|}
\hline Week 4 & $\begin{array}{l}\text { Kolmogorov } \\
\text { Smirnov test }\end{array}$ & Anderson Test & Chi-Square Test \\
\hline Logistic & 31 & 6 & 34 \\
\hline Log-logistic & 6 & 14 & 22 \\
\hline Normal & 34 & 10 & 29 \\
\hline Log-normal & 12 & 22 & 22 \\
\hline Gumbel & 40 & 4 & 10 \\
\hline Exponential & 41 & 46 & 39 \\
\hline Rayleigh & 47 & 44 & 43 \\
\hline Rician & 48 & 48 & 42 \\
\hline
\end{tabular}

Table 6 (a): Goodness of Fit tests on week 5 call drop rates

\begin{tabular}{|c|c|c|c|}
\hline Week 5 & $\begin{array}{c}\text { Kolmogorov } \\
\text { Smirnov test }\end{array}$ & Anderson Test & Chi-Square Test \\
\hline Logistic & 0.34596 & 9.7407 & 18.87 \\
\hline Log-logistic & 0.30612 & 14.559 & 15.011 \\
\hline Normal & 0.3536 & 10.011 & 19.52 \\
\hline Log-normal & 0.35748 & 20.942 & 34.39 \\
\hline Gumbel & 0.40295 & 8.9953 & 12.523 \\
\hline Exponential & 0.52399 & 167.23 & 90.816 \\
\hline Rayleigh & 0.73547 & 249.21 & 158.4 \\
\hline Rician & 0.73547 & 249.21 & 158.4 \\
\hline
\end{tabular}

Table 6 (b): Goodness of Fit tests score on week 5 call drop rates

\begin{tabular}{|c|c|c|c|}
\hline Week 5 & $\begin{array}{l}\text { Kolmogorov } \\
\text { Smirnov test }\end{array}$ & Anderson Test & Chi-Square Test \\
\hline Logistic & 13 & 5 & 11 \\
\hline Log-logistic & 6 & 13 & 9 \\
\hline Normal & 15 & 7 & 12 \\
\hline Log-normal & 17 & 30 & 21 \\
\hline Gumbel & 33 & 3 & 7 \\
\hline Exponential & 43 & 45 & 41 \\
\hline Rayleigh & 48 & 48 & 40 \\
\hline Rician & 49 & 49 & \\
\hline
\end{tabular}

\section{$\bar{s}$}

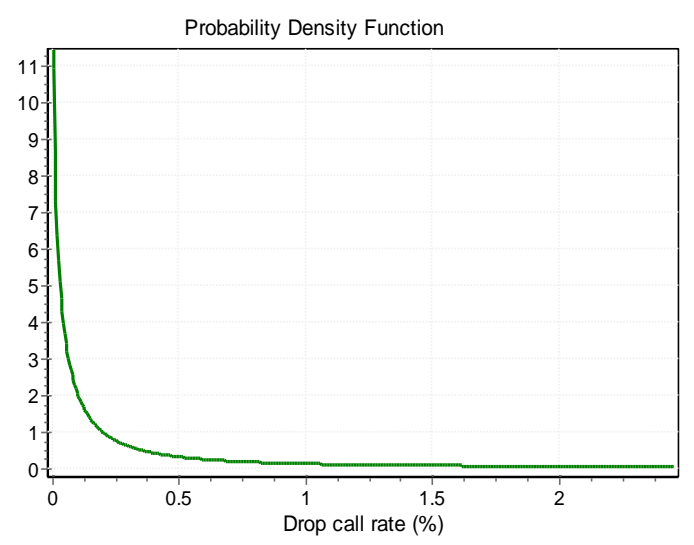

— Log-Logistic $(0.80955 ; 0.11692)$

Fig.1. Pdf of drop call rates in week 1 


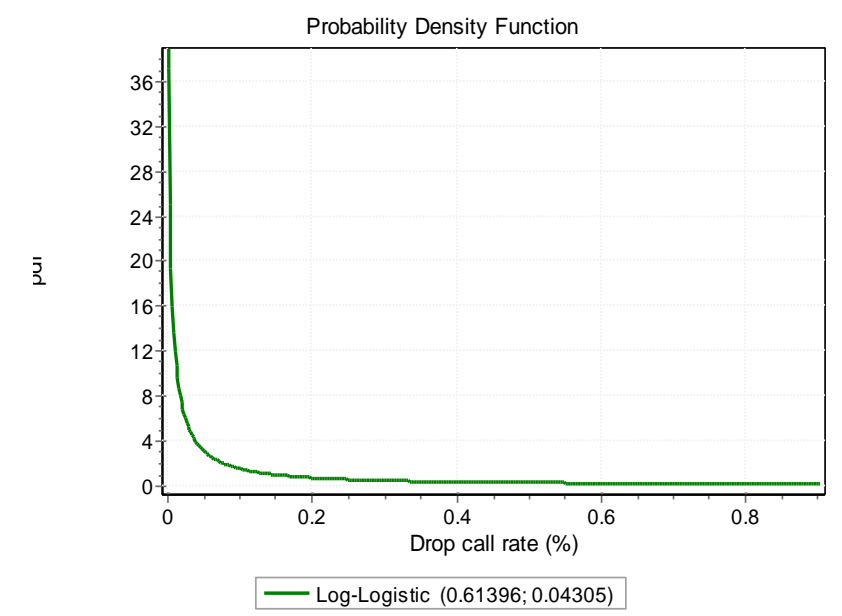

Fig.2. Pdf of drop call rates in week 2.

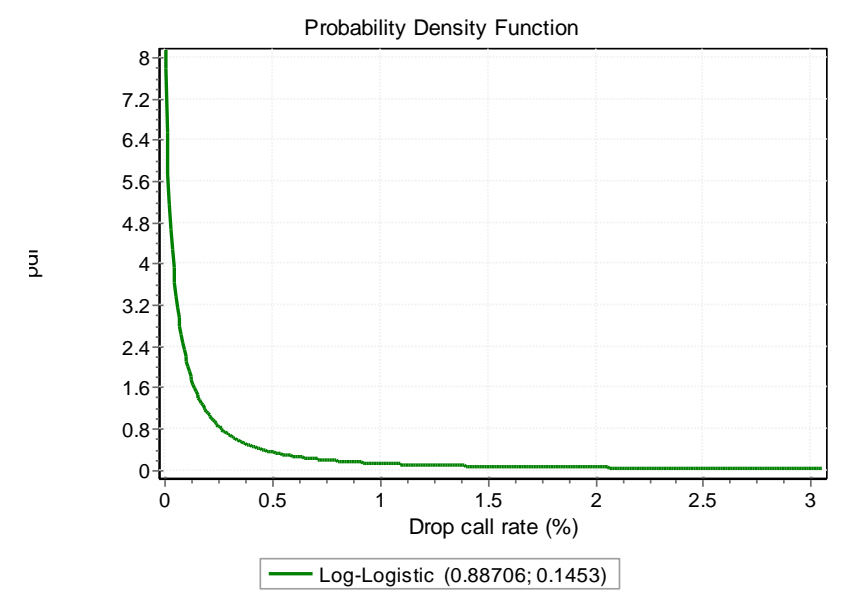

Fig.3. Pdf of drop call rates in week 3.

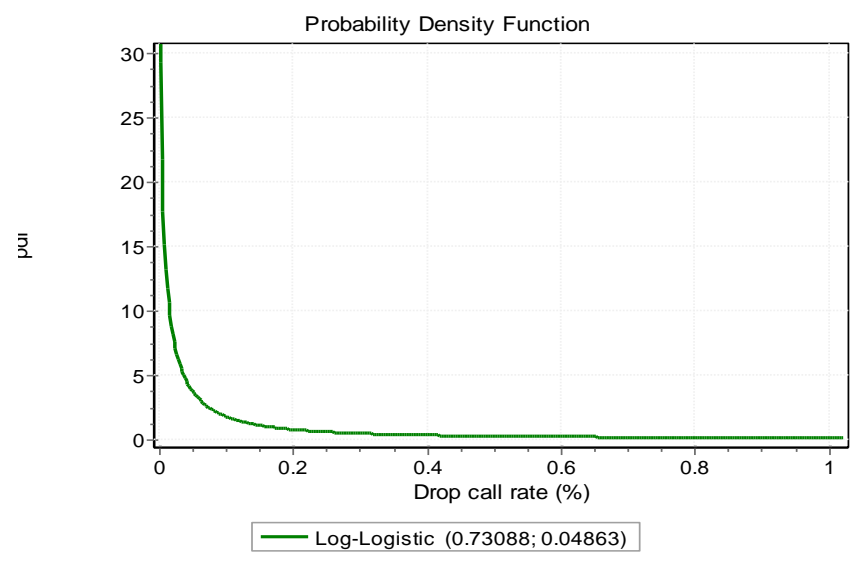

Fig. 4. Pdf of drop call rates in week 4. 


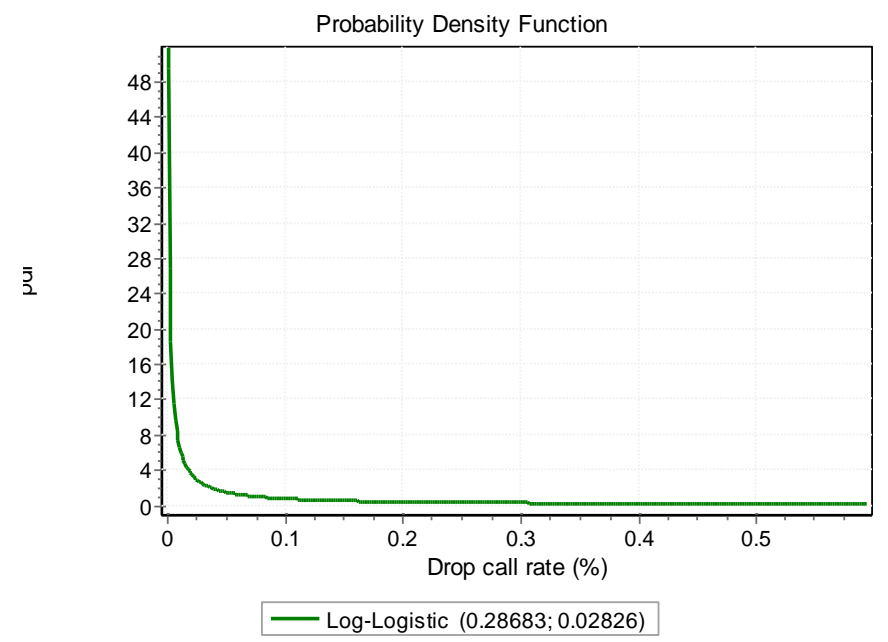

Fig. 5. Pdf of drop call rates in week 5.

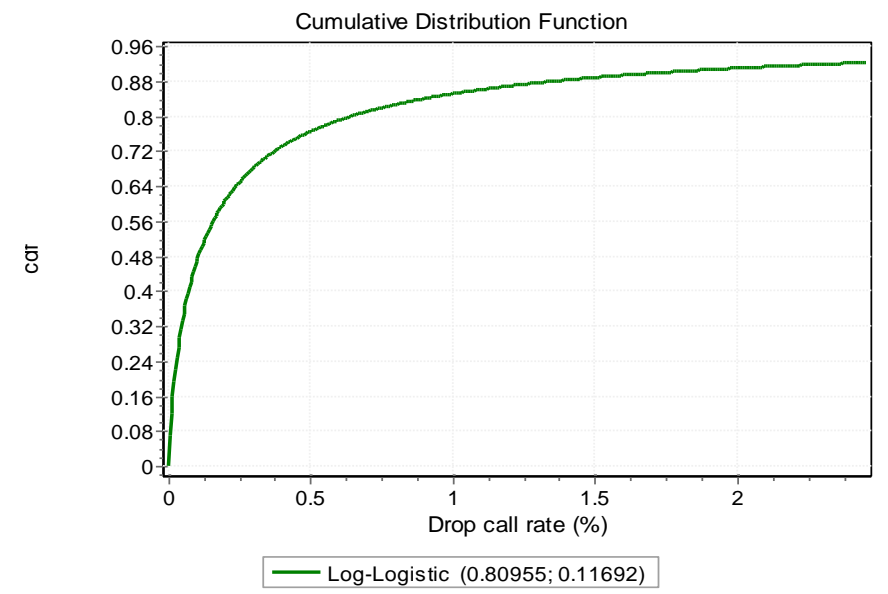

Fig. 6. cdf of drop call rates in week 1.

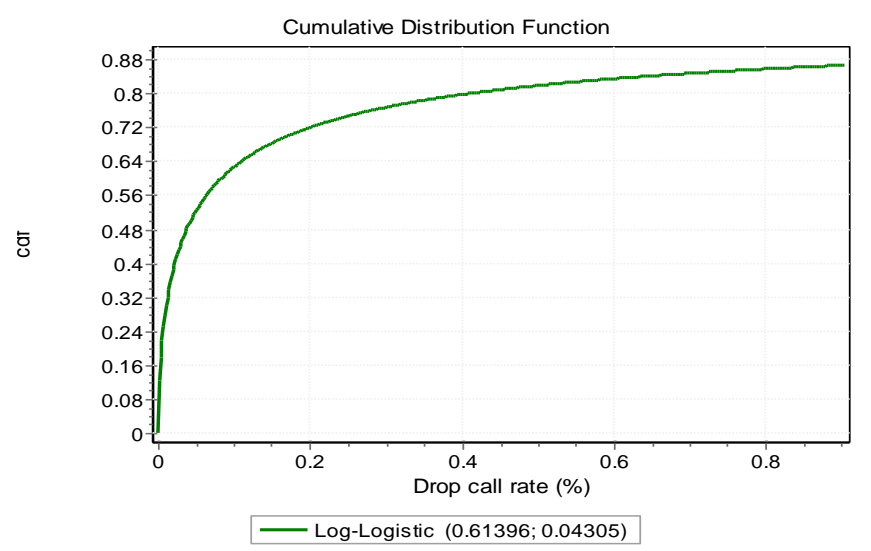

Fig.7. cdf of drop call rates in week 2. 


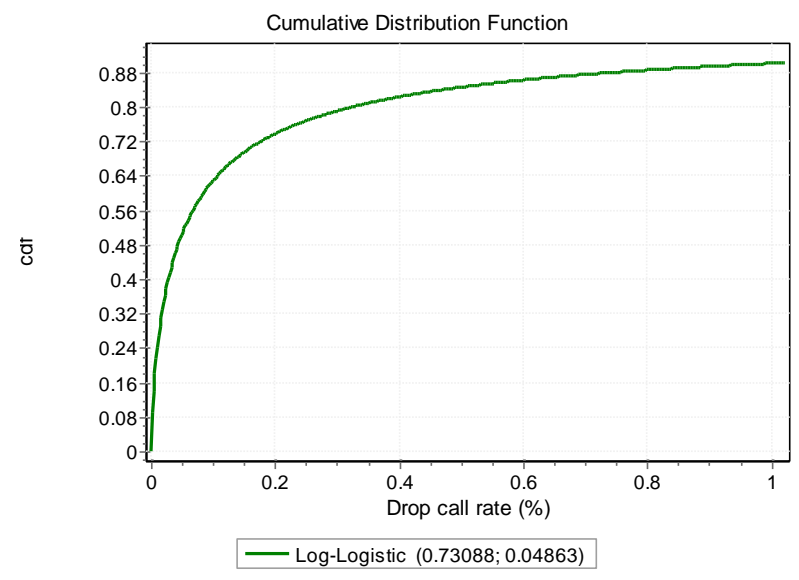

Fig.8. cdf of drop call rates in week 3.

¿ᄒ

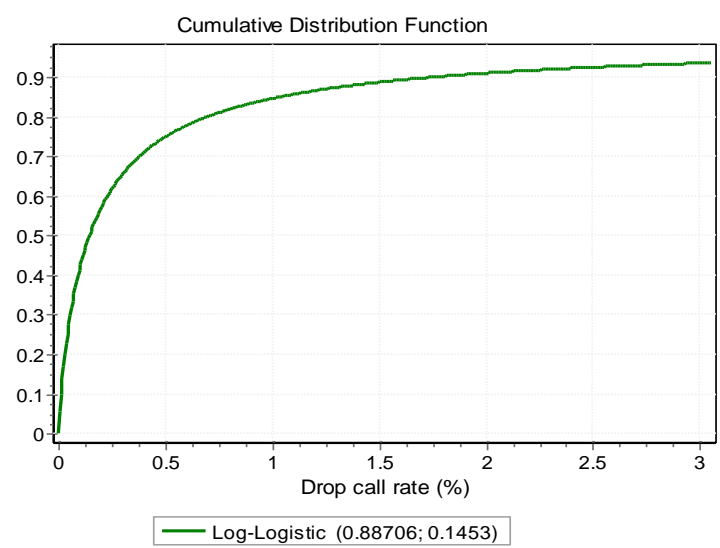

Fig.9. cdf of drop call rates in week 4 .

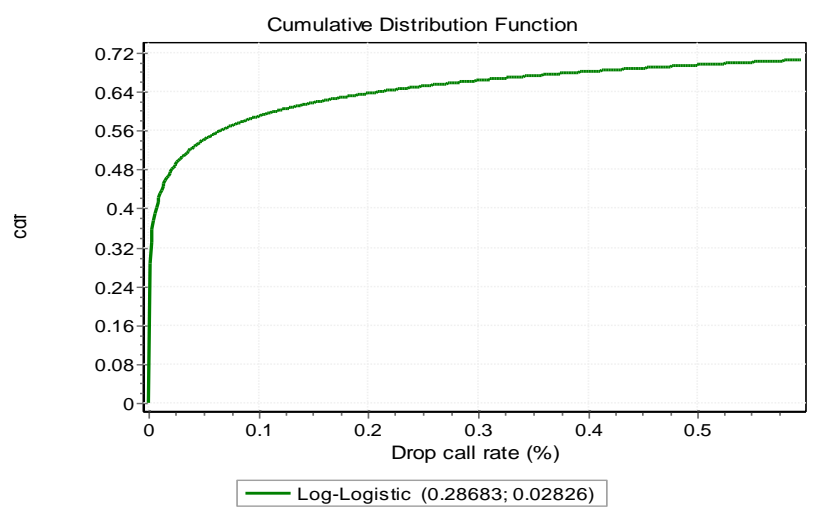

Fig.10.cdf of drop call rates in week 5.

\section{Conclusion}

The design, analysis and characterization of operational cellular communication system networks performance via realistic modeling and evaluation, also aid their effective network re-planning and performance management process.

This work was designed to determine the optimal probability distribution model for effective drop call rates analysis and characterization based on a five week acquired rate of drop calls data sample in the Southern regions of Nigeria. To accomplish the aim, eight different probability distributions namely logistic, log-logistic, normal, lognormal, exponential, Rayleigh, rician and Gumbel max were explored for drop call rates analysis and characterization. From the results, the profound performance of the log-logistic probability distribution over others is clearly shown. The results are conveyed using goodness of fit (GOF) statistics, after applying these distributions to a week call drop rates data obtained over GMS/WCDA cellular radio networks. 


\section{References}

[1] Soldani, D, Li,Mand Cuny, R. ' 'QoS and QoE Management in UMTS Cellular Systems', John Wiley \& Sons, Chichester, UK, 2006.

[2] Islam, M.S. and Niaz, A.Z.M, “Analysis of Service Quality and Satisfaction Level of Customers in Backing Sector of Banglandesh', British Journal of Marketing Studies Vol.2, No.7, pp.14-28, November 2014

[3] Isabona, J and Srivastava, V.M, "User-Centric Methodology for Objective Assessment of Service Quality in Established Wireless Mobile Communication Networks", International Journal on Communications Antenna and Propagation, Vol. 7, (1), pp. 226-30, 2017. DOI: 10.15866/irecap.v7i1.10475 26

[4] Isabona, J and Ekpenyong, M, "End-User Satisfaction Assessment Approach for Efficient Network Performance Monitoring in Wireless Communication Networks", African Journal of Computing and ICT, vol. 8. No. 1, pp. 1-16.

[5] Sudhindra, K.R and Sridhar, V, "Root cause detection of cal drops in live GSM", IEEE TENCON 2011.

[6] Fang, Y, "Modeling and Performance Analysis for Wireless Mobile Networks: A New Analytical Approach", IEEE/ACM Transactions on Networking, vol. 13 (5), pp. 989-1002, 2005.

[7] Praveen Kumar,Vinay Prakash Sriwastava, Rishi Srivastava "Decreasing Call Blocking and Dropping Rate by Implementing Resource Planning Model Through Auxiliary Station in Search MODE"“Computer Science and Engineering BBD University Lucknow, India ” I JIRSE Journals Vol 2,Issue-5-May 2014

[8] Allam Moousa, n-Najah National University, Palestine, "Prioritization Schemes in Queuing Handoff and New Calls to Reduce Call Drops in Cellular System" 52 International Journal of Mobile Computing and Multimedia Communications-3(2),5261,April-june 2011

[9] Dajab, D.D, Tarka, S.N. and Bajoga, B.G, "Simulation and Analysis of Drop-call Probability Model: A Case Study of MTEL", Nigerian Journal of Engineering, Vol. 16, No. 1, 2009

[10] Sun, H and Williamson,C, "Simulation Evaluation of Call Dropping Policies for Stochastic Capacity Networks", Department of Computer Science University of Calgary, Calgary, AB, Canada T2N 1N4, 2005.

[11] Boggia, G, Camarda, P. and D’Alconzo, A, "Modeling of Call Dropping in Well-Established Cellular Networks", EURASIP Journal on Wireless Communications and Networking, Vol. 2007, Article ID 17826, October, 2007

[12] Boggia, G., Camarda, P., D’Alconzo, A. De Biasi , A. and Siviero, M, “Drop Call Probability in Established Cellular Networks: from Data Analysis to Modeling", DEE - Politecnico di Bari, Via E. Orabona, 4 - 70125 Bari (Italy), Proc. IEEE VTC Spring 2005.,Vol. 5, pp2775-2779, 2005

[13] Ekpenyong M, and Isabona, J, “An Enhance SINR- Based Call admission Control in 3G Networks, International Journal of Wireless and Mobile Networks (IJWMN) Vol. 3, No. 5, pp 49-64, 2011.

[14] Atenaga, M and Isabona, J, ' On the Compromise between Network Performance and End User Satisfaction over UMTS Radio Interface: An Empirical Investigation, International Journal of Advanced Research in Physical Science (IJARPS)" Vol. 1, Issue 7, PP 9-18, 2014.

[15] Isabona, J, and and Obahiagbon, K, "A Practical Optimisation method to Improve QoS and GoS Based Key Performance Indicators in GSM Network Cell Cluster Environment, International Journal of Wireless and Mobile Networks, (IJWMN) Vol. 6, No. 5, pp 93-107, 2014.

[16] Isabona, J " Maximizing Coverage and Capacity with QoS Guarantee in GSM Network by means of Cell Cluster optimization, International Journal of Advanced Research in Physical Science (IJARPS) Vol. 1, Issue 6, PP 44-55, 2014.

[17] Isabona, J, "Real time Monitoring of Service Quality of a deployed UMTS Wireless Network in Campus Environment-An Optimization Perspective", International Journal of Information Science and Systems, vol.2, No.3, pp 1-16, 2013.

[18] Isabona, J. "Maximizing Coverage and Capacity with QoS Guarantee in GSM Network by means of Cell Cluster optimization", International Journal of Advanced Research in Physical Science (IJARPS) Vol. 1, Issue 6, PP 44-55,, 2014.

[19] Isabona, J, and Srivastava, V.M, "Real-Time Signal Coverage and Quality Monitoring Towards Performance Optimisation in Contemporary Mobile Broadband Cellular Networks", Research Journal of Applied Sciences Vol. 13 (4), pp. 235-240, (2018)

[20] Elizabeth N. Onwuka, Michael Okwori, Salihu O. Aliyu, Stephen S. Oyewobi, Caroline O. Alenoghena, Habeeb Bello-Salau, Sani S. Makusidi, and Victor Asuquo," Survey of Cellular Signal Booster", International Journal of Information Engineering and Electronic Business(IJIEEB), Vol.10, No.6, pp. 21-31, 2018. DOI: 10.5815/ijieeb.2018.06.03

[21] Isabona, J.and and Oghu, E., "Modelling based Quantitative Assessment of Operational LTE Mobile Broadband Networks Reliability: a Case Study of University Campus Environ", IOSR Journal of Electronics and Communication Engineering (IOSR-JECE), vol.15 (1).22-31, 2020. DOI: 10.9790/2834-1501012231

[22] Bamidele Moses Kuboye, Boniface Kayode Alese, Olumide Sunday Adewale, Samuel Oluwole Falaki,"Multi-Level Access Priority Channel Allocation with Time Threshold in Global System for Mobile Communications (GSM) Networks", International Journal of Information Technology and Computer Science(IJITCS), vol.7, no.11, pp.17-28, 2015. DOI: 10.5815/ijitcs.2015.11.03

[23] Vincent Omollo Nyangaresi, Silvance Abeka, Anthony Rodrigues, " Multivariate Probabilistic Synthesis of Cellular Networks Teletraffic Blocking with Poissonian Distribution Arrival Rates", International Journal of Wireless and Microwave Technologies(IJWMT), Vol.8, No.4, pp. 14-39, 2018.DOI: 10.5815/ijwmt.2018.04.02

[24] Ekpenyong M, and Isabona, J. "Performance Modeling of Blocking Probability in Multihop Wireless Networks", Journal of applied science \& engineering technology, vol.2, pp 33-41, 2011.

[25] Ekpenyong, $\mathrm{M}$ and Isabona, J, "Modeling the Effect of Dropped Calls Cell Traffic in Established 3G-Based Cellular Networks, African Journal of Computing and ICT, vol. 7, No. 2, pp 157-163, 2014.

[26] Ekpenyong M, and Isabona, J. (2011). “Quantifying GoS and QoS in CDMA cellular networks',Elixir Network Engg. (34) 2630-2635. www.elixirjournal.org

[27] Ekpenyong M.E and Isabona, J, "Traffic Delay Estimation for 3G Mobile IP Services", World Journal of Applied Science and Technology, Vol.4. No 2, pp 158-166, 2012. 
[28] Ekpenyong M, Eromosele.G and Isabona, J, "On the performance modeling of outage probability in CDMA wireless networks", Journal of Engineering Science and Technology Review, vol.4 (1) 74-82, 2011.

[29] Isabona, J, Azi. S.O and Ekpenyong, M., (2011). "Enhanced Spectral Utilization of 3G WCDMA-Based FDD Mode in the Uplink Transmission, Modern Applied Science www.ccsenet.org/mas Vol. 5, No. 1; pp 117-132.

[30] Ojuh.O. Divine and Isabona, J, “Application of Supervised Machine Learning Based on Gaussian Process Regression for Extrapolative Cell Availability Evaluation in Cellular Communication Systems". Communications in Computer and Information Science, book Series, CCIS vol. 1350, pp. 93-106, 2021. Springer, Cham. https://doi.org/10.1007/978-3030-69143-1_11.

[31] Isabona, J, "Parametric Maximum Likelihood Estimator combined with Bayesian and Akaike Information Criterion for Realistic Field Strength Attenuation Estimation in Open and Shadow urban Microcells", Journal of Emerging Trends in Engineering and Applied Sciences (JETEAS) vol. 10 (4), pp.151-156, 2019.

[32] Sanjiv Kumar, Pradeep Gupta, Ghanshyam Singh and Chauhan, D.S, "Performance Analysis of Rayleigh and Rician Fading Channel Models using Matlab Simulation", International Journal of Intelligent Systems Technologies and Applications 05(9):94-102, 2013. DOI: 10.5815/ijisa.2013.09.11

\section{Authors' Profiles}

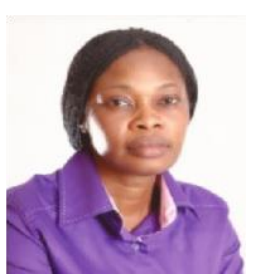

Dr. (Mrs.) O. D. Ojuh is an academic staff of Benson Idahosa University, Benin City, where she lectures Physics. She obtained her Ph.D. and M.Sc in Theoretical/ Mathematical Physics at the University of Benin City, Nigeria in 2012 and 2007 respectively and a B.Sc in Physics in 1996, from then Edo State University now known as Ambrose Alli University, Ekpoma, Edo State. Her research interests are Computational condensed matter physics/materials Science for renewable energy applications and Physics of radio signal propagation engineering. She can be reached through Email dojuh@biu.edu.ng.

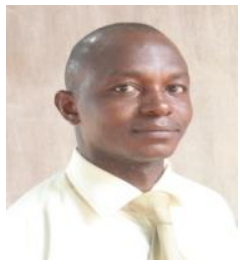

Joseph Isabona, Ph.D, received Ph.D. and M.Sc. degrees in Communication Electronics, 2013 and 2007 respectively, and a B.Sc in Applied Physics in 2003. He is the author of more than 100 scientific contributions including articles in international refereed Journals and Conferences in the area of Wireless Mobile communications. The Author is a Postdoctoral Research Fellow of the Department of Electronic Engineering, Howard College, University of KwaZulu-Natal, Durban, South Africa. His area of interest includes Signal Processing, Radio Resource Management and Physics of radio signal propagation engineering. She can be reached with josabone@yahoo.com.

How to cite this paper: Divine O. Ojuh, Joseph Isabona," Empirical and Statistical Determination of Optimal Distribution Model for Radio Frequency Mobile Networks Using Realistic Weekly Block Call Rates Indicator ", International Journal of Mathematical Sciences and Computing(IJMSC), Vol.7, No.3, pp. 12-23, 2021. DOI: 10.5815/ijmsc.2021.03.02 